\title{
Complications of Percutaneous Endoscopic Gastrostomy in Children: A Single Centre Experience
}

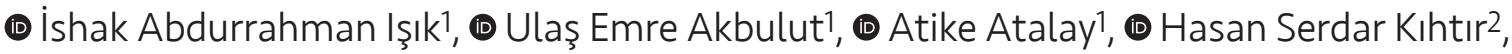 \\ (D) Yasin Bayram³
}

\author{
1University of Health Sciences Turkey, Antalya Training and Research Hospital, Clinic of Pediatric Gastroenterology Hepatology and Nutrition, \\ Antalya, Turkey \\ 2University of Health Sciences Turkey, Antalya Training and Research Hospital, Clinic of Pediatric Intensive Care Unit, Antalya, Turkey \\ 3University of Health Sciences Turkey, Antalya Training and Research Hospital, Clinic of Pediatrics, Antalya, Turkey
}

\begin{abstract}
Aim: The aim of this study was to investigate the complications of percutaneous endoscopic gastrostomy in children.

Materials and Methods: Ninety-one pediatric patients treated with percutaneous endoscopic gastrostomy (PEG) insertion by pull technique in a five-year period were enrolled into this study. Their hospital records were reviewed retrospectively for their demographic data, their primary diseases causing nutritional insufficiency, and any major or minor complications after PEG insertion.

Results: The 91 patients who were included in this study were aged between 1 month and 18 years (median 79 months). 45.1\% ( $n=41)$ of the patients were female. The majority of the patients $(76.9 \%, n=70)$ had neurological diseases. Nineteen patients $(20.9 \%)$ had metabolic diseases and two patients had cystic fibrosis (2.2\%). We observed 37 (40.7\%) complications in total. Three (3.3\%) of them were major and 34 (37.4\%) of them were minor complications.

Conclusion: Endoscopic percutaneous gastrostomy placement is an important way to continue enteral feeding in children. Although PEG is a minimally invasive technique, there are some problems which may be experienced by the children and their parents after PEC insertion, the majority of the these being minor complications.
\end{abstract}

Keywords: Percutaneous endoscopic gastrostomy, complication, children

\section{Introduction}

Gastrostomy is used widely to enable enteral feeding in those patients who cannot intake enough nutrition orally for various reasons in the presence of a functional gastrointestinal system (1). Enteral feeding is cheaper than parenteral feeding. It also maintains gut functions, inhibits bacterial translocation and prevents complications of parenteral nutrition (2). Gastrostomy can be applied surgically (3) or endoscopically as first defined by Gauderer et al. (4) in 1980. The endoscopic technique, which is less invasive than the surgical technique, also prevents long-term hospital stays, causes less incisional pain and

\footnotetext{
Address for Correspondence

ishak Abdurrahman Işık, University of Health Sciences Turkey, Antalya Training and Research Hospital, Clinic of Pediatric Gastroenterology Hepatology and Nutrition, Antalya, Turkey 
allows for early feeding $(1,5)$. Therefore, the percutaneous endoscopic gastrostomy (PEG) placement technique has become a commonly used method in pediatric patients and can be safely used by pediatric gastroenterologists even for small infants to enable enteral feeding (6).

This relatively minimal invasive method has some major and minor complications estimated to be between $4 \%$ and 44\% (5,7-9). McSweeney and Smithers (6) reported the major and minor complication rates to be $10.5 \%$ and $16.5 \%$ respectively in their study on children in 2016. Lalanne et al. (9) reported $43 \%$ early and $56 \%$ late complications ( $85 \%$ of them were minor) (8).

The aim of this study was to investigate the complications of PEG in children in a tertiary center in Turkey.

\section{Materials and Methods}

This retrospective study was carried out in the Antalya Training and Research Hospital, Clinic of Pediatric Gastroenterology in Antalya, Turkey. All pediatric patients treated with PEG insertion by pull technique between June 2014 and May 2019 were enrolled in the study. Patients who underwent gastrostomy insertion surgically and those whose information could not be obtained from the hospital records were excluded from the study.

The hospital records were reviewed retrospectively for the demographic data of the patients, their primary diseases causing nutritional insufficiency and their major or minor complications after PEG insertion.

Gastric perforation, gastro-colic fistula, internal leakage, track dehiscence, peritonitis, periprocedural aspiration pneumonia, subcutaneous abscess, bleeding, gastric outlet obstruction, cellulites/necrotizing fasciitis, massive pneumoperitoneum, or buried bumper syndrome (internal fixation device migrates along with the tract of the stoma outside the stomach) were accepted as major complications and tube blockages, tube dislodgements, tube degradation, external leakage, unplanned removal, transient gastroparesis, gastric wall ulceration or site infections were accepted as minor complications (5).

The study was approved by the local ethics committee (Antalya Education and Research Hospital Ethics Committee of Clinical Investigations, no: 2019-155; date: 16 ${ }^{\text {th }}$ May, 2019).

\section{Statistical Analysis}

Statistical analysis was performed by SPSS 18.0 software package (SPSS Inc. Chicago, IL). Categorical variables were expressed as frequencies and percentage and numerical variables as mean/median (range). Shapiro-Wilk test was used to determine the normality of data distribution. The age of the patients was expressed as median because of the abnormal distribution by Shapiro-Wilk test.

Correlation analyses were evaluated with Spearman's correlation test. A p-value of less than 0.05 was considered to be statistically significant.

\section{Results}

Ninety-one patients were included in this study aged between 3 months and 18 years (median: 79.5 months). $45.1 \%(n=41)$ of the patients were female. The majority of the patients $(76.9 \%, n=70)$ had swallowing dysfunction due to neurological diseases. The demographic characteristics and primary diseases of the patients are shown in Table I.

\begin{tabular}{|c|c|c|}
\hline \multicolumn{3}{|l|}{ Demographics } \\
\hline Age (months) & Median & $79(3-216)$ \\
\hline $\operatorname{Sex}[n(\%)]$ & Female & $41(45.1 \%)$ \\
\hline Primary disease & & [n (\%)] \\
\hline \multicolumn{2}{|c|}{ Neurological diseases } & $70(76.9 \%)$ \\
\hline & Cerebral palsy & $54(59.3)$ \\
\hline & $\begin{array}{l}\text { Sequela of traffic } \\
\text { accident }\end{array}$ & $4(4.4)$ \\
\hline & Hydrocephalus & $3(3.3)$ \\
\hline & $\begin{array}{l}\text { Hypoxia due to } \\
\text { aspiration }\end{array}$ & $2(2.2)$ \\
\hline & $\mathrm{HIE}^{*}$ & $2(2.2)$ \\
\hline & $\begin{array}{l}\text { Spinal muscular } \\
\text { atrophy }\end{array}$ & $2(2.2)$ \\
\hline & $\begin{array}{l}\text { Congenital muscular } \\
\text { dystrophy }\end{array}$ & $1(1.1)$ \\
\hline & $\begin{array}{l}\text { Hypoxia due to status } \\
\text { epilepticus }\end{array}$ & $1(1.1)$ \\
\hline & Oncological disease & $1(1.1)$ \\
\hline \multicolumn{2}{|c|}{ Metabolic diseases } & $19(20.9 \%)$ \\
\hline & Mitochondrial diseases & $4(4.4)$ \\
\hline & MPS* type 1 & $3(3.3)$ \\
\hline & Tay-sacs disease & $2(2.2)$ \\
\hline & Canavan disease & $1(1.1)$ \\
\hline & Pompe disease & $1(1.1)$ \\
\hline & Undiagnosed & $8(8.9)$ \\
\hline \multicolumn{2}{|l|}{ Cystic fibrosis } & $2(2.2)$ \\
\hline
\end{tabular}


The follow-up period of our patients varied from 6 months to 5 years (mean $2.34 \pm 2.45$ year). Three of the patients (3.3\%) had ventriculoperitoneal (V/P) shunt and one patient (1.1\%) had intraabdominal baclofen pump.

Totally, 37 (40.7\%) of the patients developed complications, three (3.3\%) of which were major and 34 (37.4\%) were minor complications. The major complications were intraabdominal abscess formation ( $n=1: 1.1 \%)$, buried bumper syndrome ( $n=1: 1.1 \%)$ and peritonitis $(n=1: 1.1 \%)$ (Table II). Intraabdominal abscess was observed in the patient with intraabdominal baclofen pump. It was drained by needle aspiration by an interventional radiologist and antibiotic was applied intravenously for three weeks. Feeding through gastrostomy was initiated after two weeks. Buried bumper syndrome was observed in one patient and it was managed by surgical intervention. The patient with peritonitis was successfully treated with parenteral antibiotic for ten days.

Thirty-four (37.4\%) minor complications were observed in our patients. Over granulation was seen in 14 patients $(15.4 \%)$, tube blockage in 6 patients $(6.6 \%)$, external leakage in 6 patients $(6.6 \%)$, tube degradation in 4 patients $(4.4 \%)$, and tube dislodgement in 4 patients (4.4\%) (Table II).

The gastrostomy tube was removed completely in four patients. Three of these were due to sufficient nutritional intake (3.3\%) (traffic accident patients $n=2$, status epilepticus patient $n=1$ ) and one of these was due to unmanaged skin lesion caused by leakage of gastric content.

The median time duration after PEG insertion and the occurrence of complications was 7 days ( 2 days- 2 years) and 14 months (2-30 months) for major and minor complications respectively. There was no correlation between major or minor complications and time duration after PEG insertion ( $p>0.05$ for both). There was also no correlation between age and complications $(p>0.05)$.

Four of the patients (4.4\%) died due to non-gastrostomy related causes during this 5 -year period.

\section{Discussion}

In 91 patients, we observed 37 (40.7\%) complications, 34 (37.4\%) of which were minor complications.

Malnutrition is a very important health issue in growing children. Gastrostomy or, in special cases, enterostomy have been recommended by ESPGHAN for those children who cannot be fed by the oral route for more than 4-6 weeks (10). Gastrostomy placement improves the course of the underlying disease, nutritional status, and decreases hospital attendance and the time needed for feeding and it also increases the quality of life of the children and their caregivers (11-13). Percutaneous endoscopic gastrostomy placement has been the preferred method in children for a long time by pediatric endoscopists $(14,15)$.

The majority of our patients had swallowing difficulties due to neurological problems $(76.9 \%, n=70)$ followed by metabolic diseases $(20.9 \%, \mathrm{n}=19)$ and cystic fibrosis $(2.2 \%$, $\mathrm{n}=2$ ). Neurological problems are also the leading cause of the PEG insertion in other studies (8,15-19).

Minor complications have been reported to be between $22 \%$ and $66.3 \%$ in the literature $(1,19-24)$. In this study, we observed 34 (37.4\%) minor complications, these were as follows; hypergranulation ( $n=14 ; 15.4 \%)$, peristomal leakage $(n=6 ; 6.6 \%)$, tube blockage $(n=6 ; 6.6 \%)$ or dislodgement $(n=4 ; 4.4 \%)$.

Hypergranulation around the tube (15.4\%) was the most common minor complication in our study. Hypergranulation with peristomal leakage are also the most reported minor complications in previous studies (5,15,25-30).

We observed $3(3.3 \%)$ major complications which were intraabdominal abscess formation $(n=1)$, peritonitis $(n=1)$ and buried bumper syndrome $(n=1)$. The major complication rate has been reported to be between $3.3 \%$ and $12.6 \%$ in the literature (1,19-24). Hansen et al. (19) and Khattak et al. (24) reported major complication rates of $2.6 \%$ and $3.3 \%$ respectively, which are similar to our major complication rate. Balogh reported a major complication rate of $10 \%$ with

Table II. Minor and major complications

\begin{tabular}{|l|l|l|l|}
\hline Minor complications & $\mathbf{n}(\mathbf{\%})$ & Major complications & $\mathbf{n}(\%)$ \\
\hline Over granulation & $14(15.4)$ & Intraabdominal abscess & $1(1.1)$ \\
\hline Tube blockage & $6(6.6)$ & Peritonitis & $1(1.1)$ \\
\hline External leakage & $6(6.6)$ & Buried bumper syndrome & $1(1.1)$ \\
\hline Tube degradation & $4(4.4)$ & & \\
\hline Tube dislodgement & $4(4.4)$ & & $3(3.3 \%)$ \\
\hline Total & $\mathbf{3 4}(\mathbf{3 7 . 4 \% )}$ & & \\
\hline
\end{tabular}


$50 \%$ of these being related with infections (1). In the same study, buried bumper syndrome, intra-abdominal bleeding and ileus were reported in 1\% of the patients (1). Our major complication rate was also comparable with their results with 2 thirds being related to infection.

The lower major complication rate in this study might be due to the fact that the majority of our patients (76.9\%) were composed of neurologically impaired patients. As defined by McSweeney and Smithers (6) these patients are under supervision due to their special conditions, so lower complication rates were reported in this group.

Buried bumper syndrome was observed in one $(1.1 \%)$ patient in this study at the end of the second year of PEC insertion. In the literature, $1.3 \%$ to $2.3 \%$ buried bumper syndrome rates have been reported, with these usually occurring in the second year (31,32).

Patients with V/P shunt have been reported to have a higher risk of complications $(22,33)$. In their study, Fortunato et al. (8) reported higher complication rates in patients with V/P shunt and oncological diseases (8). We observed no complication in our patients with V/P shunt. This might be due to the low number of patients with V/P shunt in our study.

There was no correlation between age and complications in our study as defined previously by Szlagatys-Sidorkiewicz et al. (15).

\section{Study Limitations}

There are some limitations of our study; firstly, the relatively low number of cases in this study and secondly, since this is a retrospective study, some minor complications might not have been reported by the families. We recommend that further prospective studies with larger numbers of patients be carried out.

\section{Conclusion}

Endoscopic percutaneous gastrostomy placement is an important way to continue enteral feeding in children with various forms of inadequate nutritional intake. Although percutaneous endoscopic technique is minimally invasive, it has some complications, the majority of which are minor complications.

\section{Ethics}

Ethics Committee Approval: The study was approved by the local ethics committee (Antalya Training and Research Hospital Ethics Committee of Clinical Investigations, no: 2019-155; date: 16th May, 2019).
Informed Consent: Informed consent was obtained from all of the parents before the procedure.

Peer-review: Externally peer-reviewed.

\section{Authorship Contributions}

Surgical and Medical Practices: I.A.I., U.E.A., A.A., Y.B., H.S.K., Concept: I.A.I., U.E.A., Y.B., H.S.K., Design: I.A.I., U.E.A., Y.B., H.S.K., A.A., Data Collection or Processing: I.A.I., U.E.A., Y.B., H.S.K., A.A., Analysis or Interpretation: I.A.I., U.E.A., Y.B., H.S.K., A.A., Literature Search: I.A.I., Writing: I.A.I., U.E.A., A.A.

Conflict of Interest: No conflict of interest was declared by the authors.

Financial Disclosure: The authors declared that this study received no financial support.

\section{References}

1. Balogh B, Kovacs T, Saxena AK. Complications in children with percutaneous endoscopic gastrostomy (PEG) placement. World J Pediatr 2019; 15:12-6.

2. Hucl T, Spicak J. Complications of percutaneous endoscopic gastrostomy. Best Pract Res Clin Gastroenterol 2016; 30:769-81.

3. Minard G. The history of surgically placed feeding tube. Nutr Clin Pract 2006; 21:626-33.

4. Gauderer MW, Ponsky IL, Izant RJ Jr. Gastrostomy without laparotomy: a percutaneous endoscopic technique. I Pediatr Surg 1980; 15:872-5.

5. Heuschkel RB, Gottrand F, Devarajan K, et al; European Society for Pediatric Gastroenterology, Hepatology, and Nutrition. ESPGHAN position paper on management of percutaneous endoscopic gastrostomy in children and adolescents. I Pediatr Gastroenterol Nutr 2015; 60:131-41.

6. McSweeney ME, Smithers C). Advances in pediatric gastrostomy placement. Gastrointest Endoscopy Clin N Am 2016; 26:169-85.

7. McSweeney $M E$, Jiang $H$, Deutsch $A$ J, Atmadja $M$, Lightdale JR. Long-term outcomes of infants and children undergoing percutaneous endoscopy gastrostomy tube placement. J Pediatr Gastroenterol Nutr 2013; 57:663-67.

8. Fortunato JE, Troy AL, Cuffari $\mathrm{C}$, et al. Outcome after percutaneous endoscopic gastrostomy in children and young adults. J Pediatr Gastroenterol Nutr 2010; 50:390-3.

9. Lalanne A, Gottrand F, Salleron J, et al. Long-term outcome of children receiving percutaneous endoscopic gastrostomy feeding. I Pediatr Gastroenterol Nutr 2014; 59:172-76.

10. Braegger C, Decsi T, Dias JA, et al. ESPGHAN Committee on Nutrition: Practical approach to paediatric enteral nutrition: a comment by the ESPGHAN Committee on Nutrition. JPGN 2010; 51:110-22.

11. Mahant S, Friedman JN, Connolly B, Goia C, Macarthur C. Tube feeding and quality of life in children with severe neurological impairment. Arch Dis Child 2009; 94:668-73.

12. Adamczyk P, Banaszak B, Szczepańska M, et al. Percutaneous endoscopic gastrostomy as a method of nutrition support 
in children with chronic kidney disease. Nutr Clin Pract 2012; 27:69-75.

13. Schmitt F, Caldari D, Corradini N, et al. Tolerance and efficacy of preventive gastrostomy feeding in pediatric oncology. Pediatr Blood Cancer 2012; 59:874-80.

14. Frohlich $T$, Richter $M$, Carbon R, Barth B, Kohler H. Review article: percutaneous endoscopic gastrostomy in infants and children. Aliment Pharmacol Ther 2010; 31:788-801.

15. Szlagatys-Sidorkiewicz A, Borkowska A, Popinska K, et al. Complications of PEG are not related to age. The result of 10-year multicenter survey. Advances in Medical Sciences 2016; 61:1-5.

16. Daveluy W, Guimber D, Uhlen $\mathrm{S}$, et al. Dramatic changes in home-based enteral nutrition practices in children during an 11year period. J Pediatr Gastroenterol Nutr 2006; 43:240-4.

17. Srinivasan R, Irvine $T$, Dalzell M. Indications for percutaneous endoscopic gastrostomy and procedure-related outcome. I Pediatr Gastroenterol Nutr 2009; 49:584-8.

18. Szlagatys-Sidorkiewicz A, Popinska K, Toporowska-Kowalska $\mathrm{E}$, et al. Home enteral nutrition in children - 2010 nationwide survey of the Polish Society for Clinical Nutrition of Children. Eur J Pediatr 2012; 171:719-23.

19. Hansen E, Qvist N, Rasmussen L, Ellebaek MB. Postoperative complications following percutaneous endoscopic gastrostomy are common in children. Acta Paediatr 2017; 106:1165-69.

20. Viktorsdottir MB, Oskarsson K, Gunnarsdottir A, Sigurdsson L. Percutaneous endoscopic gastrostomy in children: a populationbased study from iceland, 1999-2010. I Laparoendosc Adv Surg Tech A 2015; 25:248-51.

21. Avitsland TL, Kristensen C, Emblem R, Veenstra M, Mala T, Bjornland K. Percutaneous endoscopic gastrostomy in children: A safe technique with major symptom relief and high parental satisfaction. J Pediatr Gastroenterol Nutr 2006; 43:624-28.

22. Vervloessem $D$, van Leersum $F$, Boer $D$, et al. Percutaneous endoscopic gastrostomy (PEG) in children is not a minor procedure: risk factors for major complications. Semin Pediatr Surg 2009; 18:93-7.

23. Fascetti-Leon F, Gamba P, Dall'Oglio L, et al. Complications of percutaneous en- doscopic gastrostomy in children: Results of an Italian multicenter observational study. Dig Liver Dis 2012; 44:655-59.

24. Khattak IU, Kimber C, Kiely EM, Spitz L. Percutaneous endoscopic gastrostomy in paediatric practice: Complications and outcome. J Pediatr Surg 1998; 33:67-72.

25. Warriner L, Spruce P. Managing overgranulation tissue around gastrostomy sites. Br J Nurs 2012; 21:S14-S6.

26. Crosby I, Duerksen DR. A prospective study of tube- and feeding-related complications in patients receiving long-term home enteral nutrition. JPEN / Parenter Enteral Nutr 2007; 31:274-77.

27. Rahnemai-Azar AA, Rahnemaiazar AA, Naghshizadian $R$, Kurtz A, Farkas DT. Percutaneous endoscopic gastrostomy: Indications, technique, complications and management. World J Gastroenterol 2014; 20:7739-51.

28. Sulkowski JP, De Roo AC, Nielsen J, et al. A comparison of pediatric gastrostomy tube placement tecniques. Pediatr Surg Int 2016; 32:269-75.

29. Schrag SP, Sharma R, Jaik NP, et al. Complications related to percutaneous endoscopic gastrostomy (PEG) tubes. A comprehensive clinical review. I Gastrointestin Liver Dis 2007; 16:407-18.

30. Rosenberger LH, Newhook T, Schirmer B, Sawyer RG. Late accidental dislodgement of a percutaneous endoscopic gastrostomy tube: an underestimated burden on patients and the health care system. Surg Endosc 2011; 25:3307-11.

31. Singh RR, Eaton S, Cross KM, et al. Management of a Complication of Percutaneous Gastrostomy in Children. Eur I Pediatr Surg 2013; 23:76-79.

32. Cyrany I, Rejchrt S, Kopacova M, Bures ). Buried bumper syndrome: A complication of percutaneous endoscopic gastrostomy. World J Gastroenterol 2016; 22:618-27.

33. McSweeney ME, Kerr J, Jiang $H$, Lightdale JR. Risk factors for complications in infants and children with percutaneous endoscopic gastrostomy tubes. J Pediatr 2015; 166:1514-9. 